\title{
Microbiological Quality of Ready-To-Eat Salads During Shelf Life and Home Refrigeration
}

\author{
Alyexandra Arienzo ${ }^{1}$, Lorenza Murgia ${ }^{2}$, Ilaria Fraudentali ${ }^{1}$, Valentina Gallo ${ }^{2}$, Riccardo Angelini ${ }^{1}$ \\ and Giovanni Antonini1, ${ }^{12}$ \\ 1 Department of Science, Roma Tre University, Viale Guglielmo Marconi 446, 00146 Rome, Italy; \\ alyexandraarienzo@gmail.com; ilaria.fraudentali@uniroma3.it; riccardo.angelini@uniroma3.it; \\ giovanni.antonini@uniroma3.it \\ 2 Interuniversity Consortium INBB National Institute of Biostructures and Biosystems, Viale delle Medaglie \\ d'Oro, 305, 00136 Rome, Italy; lorenza.murgia@uniroma3.it; valentina.w@inwind.it; \\ * Correspondence: giovanni.antonini@uniroma3.it;
}

Received: date; Accepted: date; Published: date

\begin{abstract}
The market of ready-to-eat salads is experiencing a noticeable growth in Europe. The commercial success of these products is linked to the growing demand for fresh, healthy and nutritionally valuable products that can be consumed without preparation time and are perceived as safe and very high-quality products. Since they are intended to be consumed without additional treatments, these ready-to-eat products are associated with a high microbiological risk. The aim of this work was to evaluate the microbiological quality and safety of ready-to-eat salads sold in widespread supermarket chains in Lazio, Italy, at the packaging date, during shelf-life and during home-refrigeration. The study also aimed to determine the differences between low, medium and high cost products. Salmonella spp., L. monocytogenes were chosen as safety indicators as specified by European regulations while total aerobic mesophilic bacteria and Escherichia coli were chosen as quality indicators as suggested by national guidelines. Analyses were performed following the ISO standards and in parallel, for the evaluation of total aerobic mesophilic bacteria, with an alternative colorimetric system, the MBS method, in order to propose a simple, affordable and accurate alternative for testing the microbiological quality of products, especially suitable for small and medium enterprises and on-site analyses.
\end{abstract}

Keywords: RTE salads; Microbiological quality; shelf-life; MBS method

\section{Introduction}

Industrialized countries have recently faced an emerging demand for healthy and time-saving dietary solutions consistent with the modification in eating habits and the reduced time available for food preparation [1-2]. In particular, the consumption of ready-to-eat salads (RTES) has experienced a noticeable increase in Europe and especially in Italy, where, following a 10\% average annual increase, $2 \%$ of the vegetable market is involved in the production of RTE vegetables, reaching a turnover of about 600 million Euros [3, 4].

The commercial success of these products is linked to the explicit and implicit services they offer: fresh, safe, healthy and nutritionally valuable products that can be consumed without preparation time are appealing to consumers who desire to improve their diet and save time [5]. Moreover, RTES are $100 \%$ edible, prevent wastes and are socially perceived as very high-quality products [6, 7].

RTE food products are minimally processed products intended to be consumed without additional treatments. RTE leafy green vegetable processing includes several steps: after a first selection and elimination of external wilted or ruined leaves, the selected leaves are cut, washed, dried and packed in plastic containers $[8,9]$. The minimal technological processing ensures the preservation of organoleptic properties but is related to a generally shorter shelf-life compared to the starting product. The average shelf-life of RTES ranges from 5 to 7 days, and, after packages have 
been opened, products can be stored at refrigeration temperatures lower than $8^{\circ} \mathrm{C}$ for maximum 2 days. Modified atmosphere packaging (MAP) has been introduced as an upgrading technology to extend shelf-life and is currently adopted by major industries but still not always implementable in SMEs, that represent an important market sector in many Countries, including Italy [10].

The main issue associate to these products is the high microbiological risk, not generally perceived, associate with their consumption. Microbiological contamination is common and inevitable in vegetables growing in soil. Typical environmental microorganisms found in soil and irrigation water contaminate plants infiltrating through roots or exposed (wounded or cut) surfaces and get internalized by the plant's coating that creates a natural biofilm that protects them from surface treatments. The microflora can be further modified by other microorganisms that come in contact with the product during each step of the production chain [11-16].

RTES are in fact involved in the transmission of foodborne pathogens: the high moisture content, the permissive $\mathrm{pH}$, the lack of stringent decontamination procedures and the impact of temperature abuse during processing, transportation and storage can further increase the risk associated to these products. The number of gastroenteritis associated to RTE vegetables has been increasing in the last years [17-20] and several outbreaks have been connected to the consumption of salads contaminated by Salmonella spp. [21], Listeria monocytogenes (L. monocytogenes) [22, 23] and Escherichia coli (E. coli) O157: H7 [24, 5]. Furthermore, RTES may have an important role in the spread of bacteria of clinical interest carrying antibiotic resistance genes $[25,26]$.

According to European Regulation (EC) No 1441/2007 the absence of Salmonella spp. and concentrations of L. monocytogenes lower than $100 \mathrm{CFU} / \mathrm{g}$ are considered essential criteria to define safety of RTES placed on the market during their shelf-life. Although no mandatory microbiological criteria include the evaluation of total aerobic mesophilic count (TAMC) or E. coli, several guidelines include these parameters as indicators of the overall microbiological quality of RTE foods' production processes $[27,28]$. High concentration levels could be indicator of an inadequate treatment a lowered shelf life and an overall higher microbiological risk. In particular, according to Portuguese guidelines [29], for RTE salads TAMC and E. coli satisfactory, acceptable and not acceptable levels are specified (Table 1).

Table 1. Satisfactory, acceptable and not acceptable TAMC and E. coli contamination levels for RTE salads according to Portuguese guidelines [29].

\begin{tabular}{cccc}
\hline Indicators & \multicolumn{3}{c}{ Contamination levels (CFU/g) } \\
\hline & Satisfactory & Acceptable & Not acceptable \\
\hline TAMC & $\leq 10^{4}$ & $>10^{4} \leq 10^{6}$ & $>10^{6}$ \\
\hline E. coli & $\leq 10$ & $>10 \leq 10^{2}$ & $>10^{2}$ \\
\hline
\end{tabular}

In the last years several research groups have studied the microbiological quality of RTES highlighting high counts of total aerobic mesophilic count, coliforms, yeasts and molds but no presence of Salmonella spp. and L. monocytogenes [30-40]. Less attention has instead been addressed to the evolution of microflora during shelf life and during home-refrigeration after package opening.

The aim of this work is to evaluate the microbiological quality and safety of RTES sold in widespread supermarket chains in Lazio, Italy, at the packaging date, during shelf-life and during home-refrigeration. The study also aims to determine the differences between low, medium and high cost RTES and the impact of MAP technology in terms of quality and safety of these products. Salmonella spp., L. monocytogenes were chosen as indicators of RTES safety wile TAMC and E. coli as indicator of RTES quality. Pathogens detection was performed following reference ISO methods as required by EU Regulation while TAMC was performed according to reference ISO and the alternative Micro Biological Survey (MBS) method. The MBS method is a colorimetric system for easy detection and the selective count of bacteria present in agro-food in water and in environmental samples [41], developed, produced and commercialized by MBS srl, 00131 Rome (Italy), a former spin-off company of Roma Tre University. The method, that has already demonstrated to efficiently carry out microbiological analyses [42-44], and its accuracy and repeatability in comparison to the reference method for TAMC has been largely demonstrated in previous works [41, 45]. 


\section{Materials and Methods}

\subsection{Evaluation of RTES microbiological quality and safety during shelf-life.}

Samples. Two different varieties of RTES were selected among the products commercially available in Italian supermarkets: baby romaine lettuce (BRL) and rocket salad (RS). Varieties were chosen from a low-cost (LC) brand, sold in a popular discount supermarket, a medium-cost (MC) store-brand, sold in a higher-priced supermarket, and a high-cost (HC) top-selling brand-name. A total of 6 production batches for each variety and each category, were analyzed at the packaging date and at expiring date (total batches=36). Two bags from the same batch were purchased on the packaging date, transported, in their primary package and under refrigeration conditions $\left(4 \pm 1^{\circ} \mathrm{C}\right)$, to the laboratory: one was immediately analyzed, the other one was stored at $4^{\circ} \mathrm{C}$ and opened and analyzed on the expiring date.

Sample preparation. Samples were prepared homogenizing 30g in $275 \mathrm{ml}$ of Buffered Peptone Water (BPW, Applichem, Darmsdadt, Germany) using a Stomacher 400, Seward, London, UK for 120 s at medium speed and serially diluted in the same diluent when needed.

Evaluation of TAMC using the pour plate method. Evaluation of TAMC was performed according to UNI EN ISO 4833-1:2013. Samples were prepared as previously described. One $\mathrm{ml}$ of the selected dilutions was transferred into the Petri dishes in triplicate, then 15 to $17 \mathrm{ml}$ of PCA agar medium (Applichem, Darmsdadt, Germany) at $45^{\circ} \mathrm{C}$ was poured into each Petri dish. Plates were inverted and incubated at $37^{\circ} \mathrm{C}$ for 72 hours. Colonies in plates with 25 to 250 colonies were counted and viable counts in the test sample per gram were calculated as follows:

$\left.\mathrm{N}=\sum \mathrm{C} /\left[\mathrm{n}_{1}+0.1 \mathrm{n}_{2}\right)\right] \times d$

where: $\mathrm{N}=$ number of colonies per $\mathrm{ml}$ or gram of sample.

$\Sigma \mathrm{C}=$ sum of all of the colonies in all plates counted.

$\mathrm{n}_{1}=$ number of plates in the lower dilution counted.

$\mathrm{n}_{2}=$ number of plates in the next higher dilution counted.

$d=$ dilution factor corresponding to the first dilution retained

Evaluation of E. coli using the pour plate method. Evaluation of beta-glucuronidase-positive E. coli was performed according to UNI EN ISO 16649-2:2010. Samples were prepared as previously described. One $\mathrm{ml}$ of the selected dilutions was transferred into the Petri dishes in triplicate, then 15 to $17 \mathrm{ml}$ of TBX agar medium (Applichem, Darmsdadt, Germany) at $45^{\circ} \mathrm{C}$ was poured into each Petri dish. Plates were inverted and incubated at $44^{\circ} \mathrm{C}$ for 24 hours. Colonies displaying the typical morphological characteristics (blue to blue-green) in plates containing 15-150 typical CFU and less than 300 total (typical and non-typical) CFU were counted and the number of CFU of $\beta$-glucuronidase-positive E. coli present in the test sample per gram were calculated as follows:

$\mathrm{N}=\sum a /\left[\left(\mathrm{n}_{1}+0,1 \mathrm{n}_{2}\right)\right] \times d$

where: $\mathrm{N}=$ number of colonies per $\mathrm{ml}$ or gram of sample.

$\sum a=$ sum of the CFU counted on all the dishes retained from two successive dilutions, at least one of which contains a minimum 15 blue CFU.

$\mathrm{n}_{1}=$ number of plates in the lower dilution counted.

$\mathrm{n}_{2}=$ number of plates in the next higher dilution counted.

$d=$ dilution factor corresponding to the first dilution retained

Evaluation of TAMC using the MBS method. The MBS method is a colorimetric system for detection and quantification of bacteria in food and water samples. TAMC using the MBS method was performed using MBS TVC vials, containing the specific lyophilized growth medium for the detection and quantification of viable mesophilic aerobic bacteria.

To start the analysis, vials were rehydrated with $10 \mathrm{~mL}$ of sterile distilled water and paraffin oil, and shaken until all the reagent was dissolved. Vials were inoculated with $1 \mathrm{~mL}$ of samples homogenate and its serial dilutions, in parallel with the reference pour plate method. All analyses were performed in triplicate. Vials were incubated at $30^{\circ} \mathrm{C}$ for 30 hours. 
The vials' medium color was periodically controlled with a thermostatic colorimeter that automatically detects the color change. A color change from blue to yellow of the reaction medium is indicative of a positive result, i.e. the presence of aerobic mesophilic bacteria [45]. The time for color change after inoculum varies according to the bacterial concentration. The time for color change was inversely related to the bacterial content of the analyzed sample: the higher the bacterial concentration, the less the time required for color change. The persistence of the starting color indicates a negative result; that is, absence of the microorganisms of interest. Regression lines were obtained plotting the time taken for the TVC vials to change color against the logarithm of the TAMC concentration obtained with the reference method.

Detection of pathogens of interest. Recovery of the pathogens of interest according to Regulation (EC) No 1441/2007 was performed according to UNI EN ISO 11290-2:2017 and UNI EN ISO 6579-1: 2017 respectively for enumeration of L. monocytogenes and for detection of Salmonella spp. Both analyses were performed on the same food homogenate.

For the enumeration of L. monocytogenes, the food homogenate was left 1 hour at room temperature and then $1 \mathrm{ml}$ was plated in 3 PALCAM agar plates in duplicate and incubated at $37^{\circ} \mathrm{C}$ for up to 48 hours. Gray-green colonies surrounded by dark brown to black halos were cultured in BHI broth overnight at $37^{\circ} \mathrm{C}$ and the confirmation was performed on using the qualitative immunoassay for the determination of Listeria monocytogenes (LISTERIA M. CARD, InterMedical, Villaricca, NA, Italy).

For the detection of Salmonella spp., the food homogenate was incubated at $37^{\circ} \mathrm{C}$ for 24 hours. After this pre-enrichment step, $1 \mathrm{ml}$ and $100 \mu \mathrm{l}$ of the pre-enrichment broth were transferred respectively in $10 \mathrm{ml}$ of Muller Kauffmann Tetrathionate Broth and Rappaport Vassiliadis broth and incubated respectively at $37^{\circ} \mathrm{C}$ and $44^{\circ} \mathrm{C}$ for 24 hours. Next, $10 \mu \mathrm{l}$ of the two selective broths were stroked in duplicate on XLD and BGA agar plates and incubated at $37^{\circ} \mathrm{C}$ for 24 hours. Five colonies (or all if $<5$ CFU) displaying the typical morphological Salmonella characteristics (pinkish red colonies on BGA and red colonies with black centers) were cultured in $\mathrm{BHI}$ broth overnight at $37^{\circ} \mathrm{C}$ and the confirmation was performed using the qualitative immunoassay for the determination of Salmonella spp. (SALMONELLA Ag CARD, InterMedical, Villaricca NA, Italy). Additionally, 5 non-suspected colonies underwent confirmation following the same procedure.

\subsection{Evaluation of RTES microbiological quality simulating home refrigeration after package opening.}

Samples. Three different varieties of RTES were selected among the products commercially available in Italian supermarkets: BRL, RS and lamb's lettuce (LL). Varieties were chosen from a LC brand, sold in a popular discount supermarket and a HC top-selling brand-name. A total of 3 production batches for each variety and each category were selected (tot=18 batches). The bags were purchased on the packaging date, transported, in their primary package and under refrigeration conditions $\left(4 \pm 1^{\circ} \mathrm{C}\right)$, to the laboratory and analyzed on the packaging date. The opened bags were resealed and analyzed after a 2-days storage at $4^{\circ} \mathrm{C}$, as per manufacturer indication, simulating homerefrigeration conditions.

Sample preparation. Samples were prepared homogenizing $30 \mathrm{~g}$ in $275 \mathrm{ml}$ of Buffered Peptone Water (BPW) using a Stomacher 400, Seward, London, UK for 120s at medium speed and serially diluted in the same diluent.

Evaluation of TAMC using the pour plate method. Evaluation of TAMC according to ISO 48331:2013 was performed as previously described.

Evaluation of TAMC using the MBS method. Evaluation of TAMC according to MBS method was performed as previously described.

Statistical analysis. Statistical analysis of variance (ANOVA) and covariance (ANCOVA) was performed using Past (Paleontological Statistics package for education and data analysis) version 3.12 for Windows. 


\section{Results}

\subsection{Evaluation of RTES microbiological quality and safety during shelf-life.}

BRL and RS samples were selected among the products commercially available in Italian supermarkets. The selected batches were chosen from a LC brand, sold in a popular discount supermarket, a MC store-brand, sold in a higher-priced supermarket, and a HC top-selling brand-name. The microbiological quality and safety of RTES was evaluated during shelf-life: the enumeration of $L$. monocytogenes, the detection of Salmonella spp. and TAMC were performed on packaging and expiring date. Table 2 shows the results obtained for pathogen recovery: all batches resulted compliant to European standards for L. monocytogenes; conversely $67 \%$ of the analyzed batches resulted positive for Salmonella spp resulting not compliant to European regulations. All the Salmonella positive batches were found to be positive both on the packaging and the expiring date.

Table 2. Pathogen recovery in RTES batches according to European Regulation (EC) No 1441/2007.

\begin{tabular}{ccc}
\hline & Salmonella spp & L. monocytogenes \\
\hline Compliant & 12 & 36 \\
\hline Non compliant & 24 & 0 \\
\hline Total & 36 & 36 \\
\hline
\end{tabular}

TAMC results for BRL and RS are displayed in Figure 1. Of all the samples analyzed only $17 \%$ displayed an acceptable level of contamination according to Portuguese guidelines $\left(10^{4}<\mathrm{CFU} / \mathrm{g}<10^{5}\right)$.

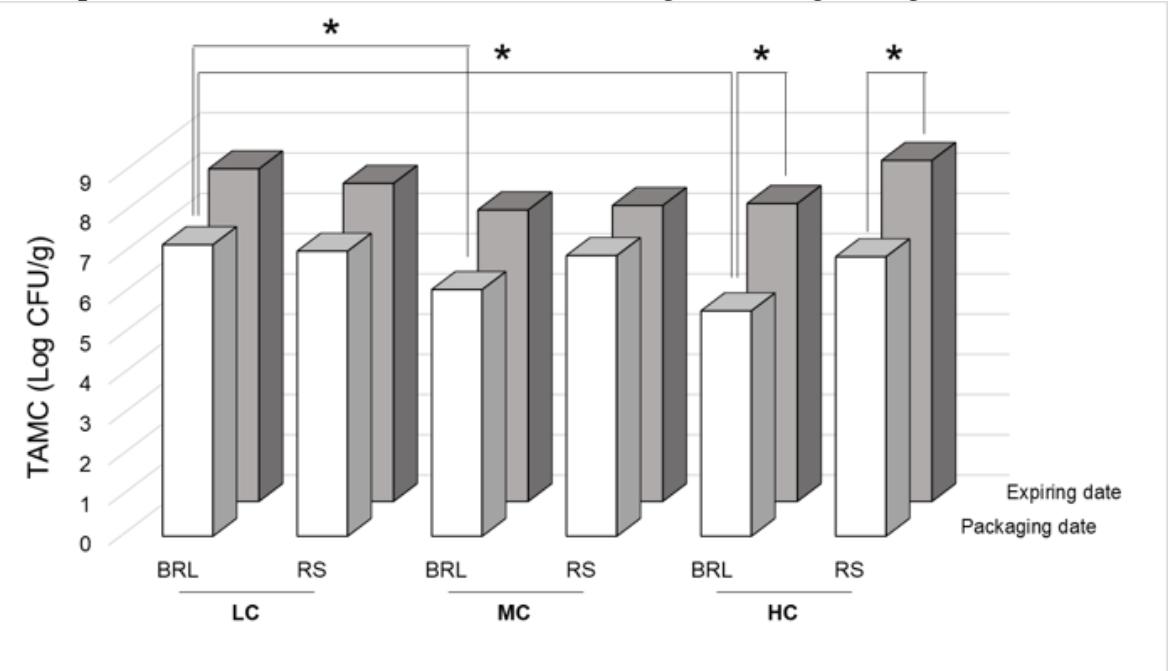

Figure 1. RTES average TAMC contamination levels at packaging and expiring date for LC, MC and HC BRL and RS samples (SD $<10 \%)$.

The average concentration at the packaging date was of $6.63( \pm 0.64)$ and $7.63( \pm 0.42) \mathrm{Log}$ CFU/g respectively with an average growth of 1 Log unit $(+15 \%)$ at the expiring date. At the packaging date $100 \%, 67 \%$ and $33 \%$ samples of BRL displayed unsatisfactory results (TAMC $>10^{6} \mathrm{CFU} / \mathrm{g}$ ) for LC, MC and HC respectively. For RS, at the packaging date $100 \%$ of LC and MC and $83 \%$ of HC samples resulted unsatisfactory (TAMC $>10^{6} \mathrm{CFU} / \mathrm{g}$ ). At the expiring date, instead, all samples, independently of the variety and the cost category displayed unsatisfactory results. A significant difference at the packaging date in TAMC for BRL was observed between LC and MC and between LC and HC samples; no significant difference was instead observed for RS samples. A significant difference between TAMC at the packaging date and expiring date was observed only for HC samples both for BRL and RS. The overall growth rates for each variety and each cost category are displayed in Table 3. 
Table 3. RTES average TAMC growth rates from packaging to expiring date for each variety and cost category.

\begin{tabular}{cccc}
\hline & LC & MC & HC \\
\hline Baby Romaine lettuce & $+11 \%$ & $+18 \%$ & $+29 \%$ \\
\hline Rocket salad & $+10 \%$ & $+5 \%$ & $+20 \%$ \\
\hline Overall & $+10,5 \%$ & $+11,5$ & $+24,5 \%$ \\
\hline
\end{tabular}

All samples resulted instead acceptable regarding the presence of E. coli that was recovered in only 1 batch of MC rocket salad in concentration < $100 \mathrm{CFU} / \mathrm{g}$.

\subsection{Evaluation of RTES microbiological quality simulating home refrigeration after package opening.}

Baby romaine lettuce, rocket salad and lamb's lettuce samples were selected among the products commercially available in Italian supermarkets. The selected batches were chosen from a LC brand, sold in a popular discount supermarket and a HC top-selling brand-name. The growth rate after package opening, simulating home-refrigeration was evaluated at the packaging date and after 2 days of storage of the open bags at $4^{\circ} \mathrm{C}$. The TAMC results for BRL, RS and LL are displayed in Figure $2(2 \mathrm{a}, 2 \mathrm{~b}$ and $2 \mathrm{c}$ respectively). At the packaging date $100 \%$ and $33 \%$ samples of the analyzed batches displayed unsatisfactory results (TAMC $>10^{6} \mathrm{CFU} / \mathrm{g}$ ) for $\mathrm{LC}$ and $\mathrm{HC}$ respectively. The average concentration at the packaging and expiring date was of $6,96( \pm 0,55)$ and 7,45 $( \pm 0,56) \mathrm{Log}$ CFU/g respectively with an overall growth of 0,5 Log unit $(+7 \%)$.
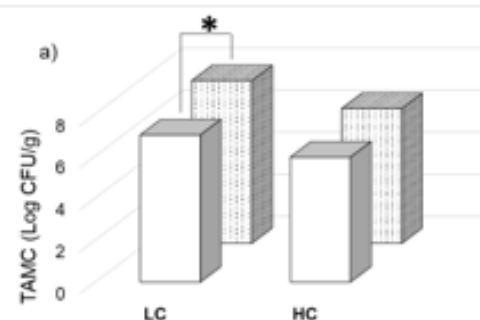

LC

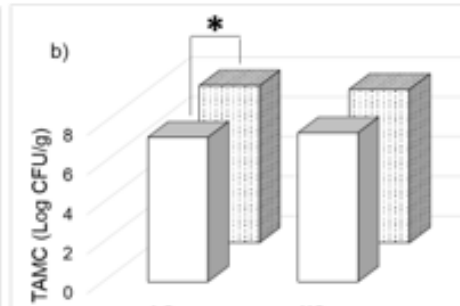

Lc
HC

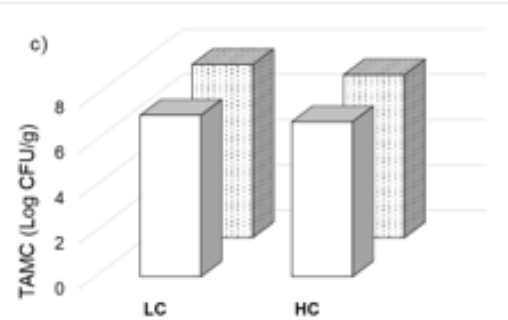

Figure 2. RTES average TAMC contamination levels at packaging date $\square$ and after 2 days of storage of the opened bags at $4^{\circ} \mathrm{C}^{-}$for LC and HC samples: 2a BRL; 2b RS samples; $2 \mathrm{c}$ LL samples (SD <10\%).

After 2 days from opening all the analyzed samples displayed a TAMC concentration $>10^{6}$ CFU/g. A significant difference between TAMC at the packaging date and after 2 days of storage of the opened bags at $4^{\circ} \mathrm{C}$ was observed only for LC BRL and RS samples; no significant difference was instead observed for HC samples independently from the variety. The overall growth rates for each variety and each cost category are displayed in Table 4.

Table 4. RTES average TAMC growth rates after packaging opening during a simulated home refrigeration of 2 days at $4^{\circ} \mathrm{C}$ for each variety and cost category.

\begin{tabular}{ccc}
\hline & LC & HC \\
\hline Baby Romaine lettuce & $+11 \%$ & $+8 \%$ \\
\hline Rocket salad & $+9 \%$ & $+3 \%$ \\
\hline Lamb's lettuce & $+7 \%$ & $+5 \%$ \\
\hline Overall & $+9 \%$ & $+5.3 \%$ \\
\hline
\end{tabular}

\subsection{Accuracy of the MBS method}

TAMC analyses were performed with the reference method and the alternative MBS method. According to ISO 16140:2016 "Linearity is the ability of a method to give results that are in proportion 
to the amount of analyte present in the sample when used with a given matrix"; that is, an increase in analyte should correspond to a linear or proportional increase in results.

The correlation between the time taken for the MBS TVC vials to change color and the log CFU/ml of TAMC is shown in Figure 3. A linear inverse relationship between the time for color change of the MBS TVC vials and the TAMC at $30^{\circ} \mathrm{C}(\log \mathrm{CFU} / \mathrm{g})$ was observed (slope=0,30; maximum analysis time $=30$ hours; $\mathrm{R}^{2}=0,79$ ) (Figure 3 ).

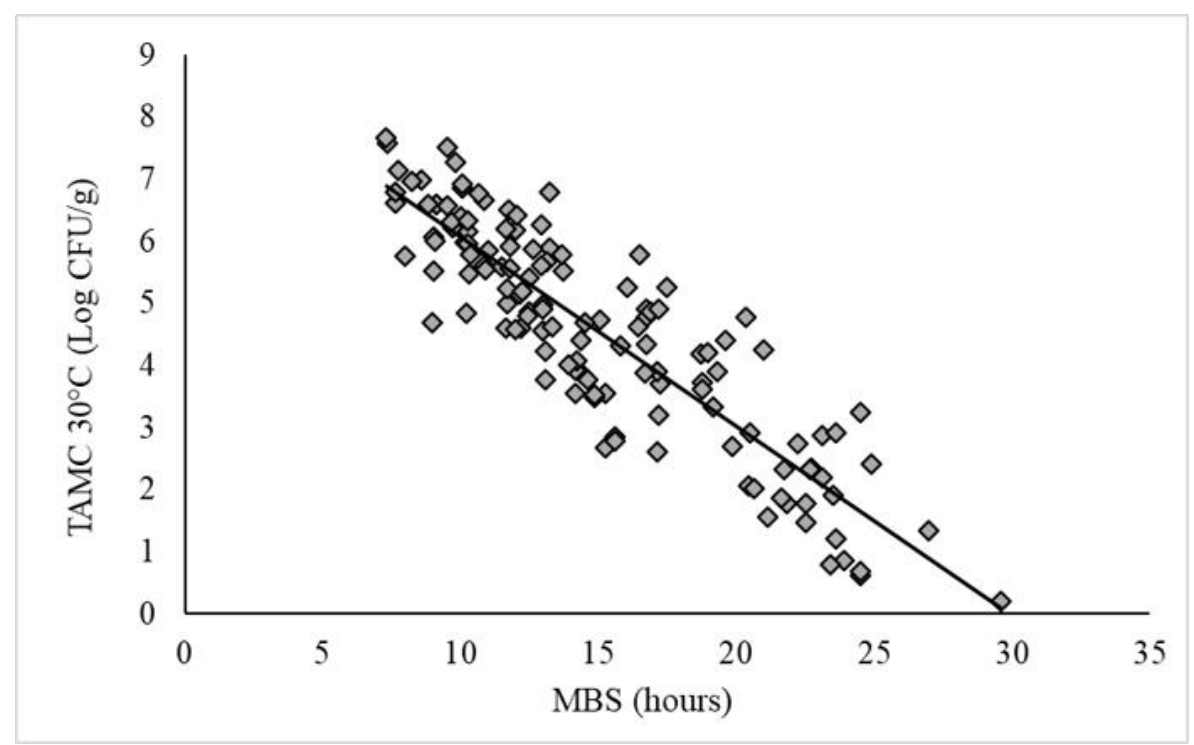

Figure 3. Correlation line between the results obtained with the MBS method and reference methods. The TAMC quantitative results obtained with reference method were plotted against the time taken for the MBS TVC vials to change color. Continuous line represents the linear regression analysis (slope $\left.=0.30, \mathrm{R}^{2}=0.79\right)$. Each analysis was performed in triplicate $(\mathrm{SD}<0.4)$.

\section{Discussion}

In this work we have analyzed the microbiological quality and safety of RTES sold in Lazio, Italy, taking into consideration different varieties and cost-categories: 36 batches were analyzed at the packaging and expiring date and 18 batches were analyzed at the packaging date and after two days from opening and storage at $4^{\circ} \mathrm{C}$ in order to monitor the presence of pathogens of interest, global growth trends during shelf-life and during a simulated domestic-refrigeration condition.

With regard to pathogens, interestingly, the prevalence of Salmonella spp. was very high (67\%) and no significant difference could be observed among the selected varieties and cost-categories; $L$. monocytogenes was instead not recovered aligning with the results obtained in other studies [34-38] The divergence between the results obtained in this work from those obtained by other groups regarding the presence of Salmonella spp. could be explained by the fact that most of the positive results following immunological confirmation were obtained from non-suspected colonies, displaying non typical morphological characteristics.

The study of TAMC during shelf-life revealed many unsatisfactory results: at the packaging date HC batches resulted less contaminated compared to LC and MC probably linked to the specific packaging conditions (MAP). At the expiring date instead, all batches displayed unsatisfactory results: an average higher growth rate has been observed in HC salads compared to LC and MC. We hypothesize that this could be due by the fact that, the MAP condition could affect the existing microflora by reducing the initial concentration and selecting specific bacteria that, in the unaltered product environment, are favored by the higher availability of nutrients and the reduced competition compared to those of LC and MC. A slightly different trend was observed simulating homerefrigeration after package opening. At the packaging date HC batches resulted less contaminated compared to LC in baby romaine lettuce while no significant difference was observed for the other samples. After two days of storage at $4^{\circ} \mathrm{C}$ of the opened bags all the analyzed samples displayed 
unsatisfactory results; the growth trends were similar to those observed during shelf-life for LC batches while they were considerably reduced for HC batches. This difference may be indicative of the fact that the modified MAP environmental condition caused by the bags' opening could in some way affect the metabolism of resident microflora.

TAMC were performed in parallel with the MBS method with satisfying outcomes. The MBS method resulted quite accurate $\left(R^{2}=0,78\right)$ and was able to detect $<5 \mathrm{CFU} / \mathrm{ml}$ in 30 hours significantly reducing the standard analytical times ( 72 hours). The simple procedure, the simplified interpretation of results and the stand-alone equipment could be very useful tool to streamline microbiological analysis particularly in small, medium enterprises.

In conclusion, the microbiological quality of RTES seems to be still a challenge despite the advances in technology and the attention from Regulations and International food safety agencies. This work uncovers important weaknesses in the supply chain and a failure of monitoring programs. The obtained results highlight the need for a more extensive microbiological control and suggest optimization of large-scale washing procedures. A more attentive analysis of the possible conditions occurring during shelf-life and domestic storage should be also considered. The implementation of an accurate, fast, easy and portable microbiological method of analysis could be a valuable tool to provide higher quality products.

Author Contributions: Conceptualization, G.A., AA and LM; methodology, A.A. and L.M.; investigation, A.A., L.M., I.F. and V.G..; resources, G.A. and R.A.; writing-original draft preparation and editing, A.A..; review, G.A.; supervision, G.A and R.A. All authors have read and agreed to the published version of the manuscript.

Funding: This study has been supported by National Funding for Centers of Excellence (Science Department, Roma Tre University - MIUR, Articolo 1, Commi 314-337 Legge 232/2016), and by LazioInnova, Innova4gamma and MBSMART Projects, - POR FESR LAZIO 2014-2020 - Progetti Integrati “KET's"- CUP H86C18000560002 and CUP F85F18000120007

Acknowledgments: We gratefully acknowledge for useful discussion the Innova4gamma workgroup: Ottavia Stalio, Cristiana Citton, Alessandra Cona, Paraskevi Tavladoraki, Simone Grasso, Laura De Gara, Giorgio Pennazza, Vittoria Locato, Marco Santonico.

Conflicts of Interest: The authors declare no conflict of interest

\section{References}

1. Betts, R. Microbial update: Fruit and salad. Int Food Hyg, 2014, 25, 9e12

2. Little, C.L.; Gillespie, I.A. Prepared salads and public health. J Appl Microbiol, 2008, 105, 1729-1743

3. Pilone, V.; Stasi, A.; Baselice, A. Quality preferences and pricing of fresh-cut salads in Italy: new evidence from market data. Brit Food J, 2017, 119(7), 1473-1486.

4. Losio, M.N.; Pavoni, E.; Bilei, S.; Bertasi, B.; Bovec, D.; Capuano, F.; Farneti, S.; Blasi, G.; Comin, D.; Cardamone, C.; Decastelli, L.; Delibato, E.; De Santis, P.; Di Pasquale, S.; Gattuso, A.; Goffredo, E.; Fadda, A.; Pisanu, M.; De Medici, D. Microbiological survey of raw and ready-to-eat leafy green vegetables marketed in Italy. Int J of Food Microb, 2015, 2010, 88-91.

5. Olaimat, A.N.; Holley, R.A. Factors influencing the microbial safety of fresh produce: A review. Food Microb, 2012, 32, 1e19.

6. de Oliveira, M.A.; de Souza, V.M.; Morato Bergamini, A.M.; Pereira De Martinis, E.C. Microbiological quality of ready-to-eat minimally processed vegetables consumed in Brazil. Food Control, 2011, 22, 1400-3

7. Abadias, M.; Usall, J.; Anguera, M.; Solsona, C.; Viñas, I. Microbiological quality of fresh, minimallyprocessed fruit and vegetables, and sprouts from retail establishments. Int J Food Microbiol, 2008, 123, 121129

8. Pinela, J.; Barreira, J.C.M.; Barros, L.; Antonio, A.L.; Carvalho, A.M.; Oliveira, M.B.P.P.; Ferreira, I.C.F.R. Postharvest quality changes in fresh-cut watercress stored under conventional and inert gas-enriched modified atmosphere packaging. Postharvest Biol Tec, 2016, 112, 55-63.

9. Brandao, M.L.L.; Almeida, D.O.; Bispo, F.C.P.; Bricio, S.M.L.; Marin, V.A.; Miagostovich, M.P. Assessment of Microbiological Contamination of Fresh, Minimally Processed, and Ready-to-Eat Lettuces (Lactuca sativa), Rio de Janeiro State, Brazil. J Food Sci, 2014, 79(5), M961-M966 
10. Oliveira, M.; Usall, J.; Solsona, C.; Alegre, I.; Vinas, I.; Abadias, M. Effects of packaging type and storage temperature on the growth of foodborne pathogens on shredded "Romaine" lettuce. Food Microbiol, 2010, 27, 375-380

11. Erickson, M.C. Internalization of Fresh Produce by Foodborne Pathogens. Ann Rev Food Sci Tec, 2012, 3, 283-310.

12. Meyer, K.M.; Leveau, J.H.J. Microbiology of the phyllosphere: a playground for testing ecological concepts. Oecologia, 2012, 168, 621-629.

13. Erickson, M.C.; Webb, C.C.; Diaz-Perez, J.C.; Phatak, S.C.; Silvoy, J.J.; Davey, L.; Payton, A.S.; Liao, J.; Ma, L.; Doyle, M.P. Surface and internalized Escherichia coli O157: H7 on field-grown spinach and lettuce treated with spray-contaminated irrigation water. J Food Prot, 2010, 73(6), 1023-1029.

14. Jay, J.M.; Loessner, M.J.; Golden, D.A. Modern Food Microbiology, 7th ed.; Springer, 2009

15. Klerks, M.M.; Franz, E.; Van Gent-Pelzer, M.; Zijlstra, C.; van Bruggen, A.H.C. Differential interaction of Salmonella enteric serovars with lettuce cultivars and plant-microbe factors influencing the colonization efficiency. ISME J, 2007, 1(7), 620-631.

16. Klerks, M.M.; Van Gent-Pelzer, M.; Franz, E.; Zijlstra, C.; Van Bruggen, A.H.C. Physiological and molecular responses of Lactuca sativa to colonization by Salmonella enteric serovar Dublin. AEM, 2007, 73(15), 49054914.

17. Callejon, R.M.; Rodríguez-Naranjo, M.I.; Úbeda, C.; Hornedo-Ortega, R.; García-Parrilla, M.C.; Troncoso, A.M. Reported foodborne outbreaks due to fresh produce in the United States and european union: Trends and causes. Foodborne Pathog Dis, 2015, 12, 32-38.

18. Castro-rosas, J.; Cerna-Cortés, J.F.; Méndez-Reyes, E.; Lopez-Hernandez, D.; Gómez-Aldapa, C.A.; EstradaGarcia, T. Presence of faecal coliforms, Escherichia coli and diarrheagenic E. coli pathotypes in ready-toeat salads, from an area where crops are irrigated with untreated sewage water. Int J Food Microbiol, 2012, $156,176-180$

19. Taban, M.B.; Halkman, K. Do leafy green vegetables and their ready-to-eat [RTE] salads carry a risk of foodborne pathogens? Anaerobe, 2011, 17, 286-7. 10.1016/j.anaerobe.2011.04.004.

20. Long, S.M.; Adak, G.K.; O’Brien, S.J.; Gillespie, I.A. General outbreaks of infectious intestinal disease linked with salad vegetables and fruit, England and Wales, 1992-2000. Comm Dis Public Health, 2002, 5, 101-105.

21. Vestrheim, D.F.; Lange, H.; Nygård, K.; Borgen, K.; Wester, A.L.; Kvarme, M.L.; Vold, L. Are ready-to-eat salads ready to eat? An outbreak of Salmonella Coeln linked to imported, mixed, pre-washed and bagged salad, Norway, November 2013. Epidemiol Infect, 2016, 144(8), 1756-60.

22. Centers for Disease Control and Prevention (CDC). Multistate Outbreak of Listeriosis Linked to Packaged Salads Produced at Springfield, Ohio Dole Processing Facility (Final Update). [Online]. 2016, Available: https://www.cdc.gov/listeria/outbreaks/bagged-salads-01- 16/index.html [Accessed 08 April 2019]

23. Stephan, R.; Althaus, D.; Kiefer, S.; Lehner, A.; Hatz, C.; Schmutz, C.; Jost, M.; Gerber, N.; Baumgartner, A.; Hachler, H.; Mausezahl-Feuz, M. Foodborne transmission of Listeria monocytogenes via ready-to-eat salad: A nationwide outbreak in Switzerland, 2013-2014. Food Control, 2015, 57, 14-17

24. Centers for Disease Control and Prevention (CDC). Multistate Outbreak of Shiga toxin-producing Escherichia coli O157: H7 Infections Linked to Ready-to-Eat Salads (Final Update). [Online]. 2013, Available: http://www.cdc.gov/ecoli/2013/O157H7-11- 13/index.html?s_cid=cs_002 [Accessed 08 April 2019]

25. Campos, J.; Mourão, J.; Pestana, N.; Peixe, L.; Novais, C.; Antunes, P. Microbiological quality of ready-toeat salads: an underestimated vehicle of bacteria and clinically relevant antibiotic resistance genes. Int $J$ Food Microbiol, 2013, 16, 166(3):464-70

26. Taban, B.M.; Aykut, S.A.; Akkoc, N.; Akcelik, M. Characterization of antibiotic resistance in Salmonella enterica isolates determined from ready-to-eat (RTE) salad vegetables. Braz J Microbiol, 2013, 44(2), 385-391

27. Food Safety Authority of Ireland (FSAI). Guidance Note No. 3: Guidelines for the Interpretation of Results of Microbiological Testing of Ready-to-Eat Foods Placed on the Market (Revision 2). 2016

28. Food Standards Australia New Zealand (FSANZ). Microbiological Quality Guide for Ready-to-Eat Foods. A Guide to Interpreting Microbiological Results. 2009.

http://www.foodstandards.gov.au/_srcfiles/Guidelines\%20for\%20Micro\%20exam.pdf

29. Santos, M.I.; Correira, C.; Cunha, M.I.C.; Saraiva, M.M.; Novais, M.R. Valores Guia para avaliação da qualidade microbiológica de alimentos prontos a comer preparados em estabelecimentos de restauração. Rev Ordem dos Farm, 2005, 64, 66-68. 
30. Calonico, C.; Delfino, V.; Pesavento, G.; Mundo, M.; Lo Nostro, A. Microbiological Quality of Ready-to-eat Salads from Processing Plant to the Consumers. J Food Nutr Res, 2019, 7(6), 427-434

31. Becker, B.; Stoll, D.; Schulz, P.; Kulling, S.; Huch, M. Microbial Contamination of Organically and Conventionally Produced Fresh Vegetable Salads and Herbs from Retail Markets in Southwest Germany. Foodborne Pathog Dis, 2018, 16(4)

32. Bencardino, D.; Vitali, L.A.; Petrelli, D. Microbiological evaluation of ready-to-eat iceberg lettuce during shelf-life and effectiveness of household washing methods. IJFS, 2018, 7(1), 6913.

33. Mogren, L.; Windstam, S.; Boqvist, S.; Vågsholm, I.; Söderqvist, K.; Rosberg, A.K.; Lindén, J.; Mulaosmanovic, E.; Karlsson, M.; Uhlig, E.; Håkansson, A.; Alsanius, B. The Hurdle Approach-A Holistic Concept for Controlling Food Safety Risks Associated With Pathogenic Bacterial Contamination of Leafy Green Vegetables. Front Microbiol, 2018, 9, 1965

34. Fiedler, G.; Kabisch, J.; Bohnlein, C.; Huch, M.; Becker, B.; Cho, G.S.; Franz, C.M.A.P. Presence of Human Pathogens in Produce from Retail Markets in Northern Germany. Foodborne Pathog Dis, 2017, 14(9)

35. Ilyas, S.; Qamar, M.U.; Rasool, M.H.; Abdulhaq, N.; Nawaz, Z. Multidrug-resistant pathogens isolated from ready-to-eat salads available at a local market in Pakistan. Brit Food J, 2016, 118(8), 2068-2075.

36. Jeddi, M.Z.; Yunesian, M.; Gorji, M.E.; Noori, N.; Pourmand, M.R.; Khaniki, G.R. Microbial evaluation of fresh, minimally-processed vegetables and bagged sprouts from chain supermarkets. J Health Popul Nutr, 2014, 32, 391e399

37. Allen, K.J.; Kovacevic, J.; Cancarevic, A.; Wood, J.; Xu, J.; Gill, B.; Allen, J.K.; Mesak, L.R. Microbiological survey of imported produce available at retail across Canada. Int J Food Microbiol, 2013, 162, 135e142.

38. Althaus, D.; Hofer, E.; Corti, S.; Julmi, A.; Stephan, R. Bacteriological survey of ready-to-eat lettuce, freshcut fruit, and sprouts collected from the Swiss market. J Food Prot, 2012, 75(7), 1338-41.

39. Marinelli, L.; Maggi, O.; Aurigemma, C.; Tufi, D.; De Giusti, M. Fresh vegetables and ready-to eat salad: phenotypic characterization of moulds and molecular characterization of yeasts", Annali di Igiene: medicina preventiva e di comunità, 2012, 24(4): 301-309.

40. de Giusti, M.; Aurigemma, C.; Marinelli, L.; Tufi, D.; de Medici, D.; di Pasquale, S.I.; de Vito, C.; Boccia, A. The evaluation of the microbial safety of fresh ready-to-eat vegetables produced by different technologies in Italy. J Appl Microbiol, 2010, 109, 996-1006

41. Arienzo, A.; Sobze, M.S.; Wadoum, R.E.G.; Losito, F.; Colizzi, V.; Antonini, G. Field Application of the Micro Biological Survey Method for a Simple and Effective Assessment of Microbiological Quality of Water Sources in Developing Countries. Int J Environ Res Public Health, 2015, 12(9), 10314-10328.

42. Losito, F.; Arienzo, A.; Bottini, G.; Priolisi, F.R.; Mari, A.; Antonini, A. Microbiological Safety and Quality of Mozzarella Cheese Assessed by the Microbiological Survey Method. J Dairy Sci, 2014, 97 (1), 46-55.

43. Losito, F.; Bottini, G.; De Ascentis, A.; Priolisi, F.R.; Mari, A.; Tarsitani, G.; Antonini, G. Qualitative and Quantitative Validation of the Micro Biological Survey Method for Listeria spp., Salmonella spp., Enterobactericeae and Staphylococcus aureus in Food Samples. Am J Food Technol, 2012, 7(6), 340-351.

44. Bottini, G.; Losito, F.; De Ascentis, A.; Priolisi, F.R.; Mari, A.; Antonini, G. Validation of the Micro Biological Survey Method for Total Viable Count and Escherichia coli in Food Samples. Am J Food Technol, 2011, 6 (11), 951-962.

45. Arienzo, A.; Losito, F.; Stalio, O.; Antonini, G. Comparison of Uncertainty Between Traditional and Alternative Methods for Food Microbiological Analysis. Am J Food Technol, 2016, 11(1-2), $29-36$. 